\title{
Corrosion behavior of low carbon steel in technological aqueous calcium nitrate solutions
}

\author{
O. Kozaderov, ${ }^{1}$ O. Kozaderova ${ }^{2}$ and S. Niftaliyev ${ }^{2}$

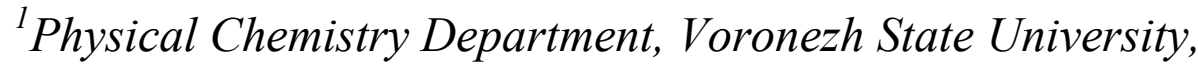 \\ Universitetskaya pl. 1, Voronezh, 394006, Russian Federation \\ ${ }^{2}$ Inorganic Chemistry and Chemical Technologies Department, Voronezh State University \\ of Engineering Technologies, pr. Revolutsii, 19, Voronezh, 394036, Russian Federation \\ E-mail: ok@chem.vsu.ru
}

\begin{abstract}
The paper demonstrates the inhibitive effect of inorganic and organic additives to calcium nitrate and ammoniated calcium nitrate aqueous solutions on corrosion of low carbon structural steel St3. The steel corrosion behavior was studied by voltammetry. The effect of ammonization as well as of addition of such inhibitors as monoethanolamine and potassium dichromate on the main parameters of the corrosion process was established. The findings will be useful for corrosion control in components made of the steel used in fertilizer industry and also in concrete as reinforcement.
\end{abstract}

Key words: ammonium calcium nitrate solutions, low carbon structural steel, corrosion, monoethanolamine, potassium dichromate.

Received: May 25, 2015.

doi: $\underline{10.17675 / 2305-6894-2015-4-3-221-225}$

\section{Introduction}

The main application areas of calcium nitrate are nitrogen fertilizers and multifunctional additives in concrete [1-3]. In both cases, addition of ammonium nitrate significantly reduces the hygroscopicity and acidity of the main component. The industrial ammoniated solution of calcium nitrate contains $35-53 \% \mathrm{Ca}\left(\mathrm{NO}_{3}\right)_{2}$ and $2-8 \% \mathrm{NH}_{4} \mathrm{NO}_{3}$. One of the basic sources of this solution is the production of compound fertilizers based on nitric acid. High density and low freezing point of the solution allow one to use it as a heavy fluid damping oil or gas wells [4]. The noticeable cryoscopic effect, in principle, allows one to apply the ammoniated calcium nitrate solution for the production of salt-based antifreeze liquids circulating in heating or cooling systems. In comparison with a toxic, flammable and explosive glycol antifreeze, the aqueous solution of salts is a nonflammable, environmentally friendly and rather cheap product [5]. At the same time, salt deposition, narrow temperature range, and especially high corrosivity significantly limit the use of concentrated salt solutions as coolants and heat transfer fluids.

A widely practiced method of corrosion protection, especially in neutral or close to neutral media, where corrosion occurs predominantly with oxygen depolarization, is addition of specially selected compounds (inhibitors) to the corrosive solution $[6,7]$. In 
this paper we study the corrosivity of the model solution of calcium nitrate (MSCN) and ammoniated solution of calcium nitrate (ASCN) with inorganic and organic additives toward structural low-carbon unalloyed steel St3.

\section{Experimental}

The investigation of the corrosivity of aqueous calcium nitrate solutions (45\% wt. $\mathrm{Ca}\left(\mathrm{NO}_{3}\right)_{2}$, and ammoniated calcium nitrate solutions $\left(45 \%\right.$ wt. $\mathrm{Ca}\left(\mathrm{NO}_{3}\right)_{2}, 6 \%$ wt. $\left.\mathrm{NH}_{4} \mathrm{NO}_{3}\right)$ was carried out at room temperature by the voltammetric method on steel St3 $(0.17 \% \mathrm{wt}$. C, $0.32 \%$ wt. $\mathrm{Mn}, 0.18 \%$ wt. Si), in the absence of additives and in the presence of potassium dichromate and monoethanolamine (1\% wt.). The acidity of all solutions was determined with a $\mathrm{pH}$-meter. A three-electrode electrochemical cell with silver chloride reference and platinum auxiliary electrodes was used. The polarization curves were obtained using an "IPC-Compact" potentiostat. The working electrode potential was varied from cathodic to anodic region at a scan rate of $10 \mathrm{mV} / \mathrm{s}$. All potentials are given in the standard hydrogen electrode scale (SHE); the currents are related to the geometrical area of the test steel electrode.

\section{Results and discussion}

The basic parameters of the corrosion process (Table 1) were determined by extrapolation of the linear portions of the anodic and cathodic curves (Figure 1) until they intersect at the point with coordinates $E_{\text {corr }}$ (corrosion potential) and $\lg i_{\text {corr }}\left(i_{\text {corr }}\right.$ is the corrosion rate in current units). The Tafel slopes of the linear parts of the polarization curves are given in Table 2.

Table 1. Basic parameters of the corrosion process on steel St3 in MSCN (numerator) and ASCN (denominator).

\begin{tabular}{cccc}
\hline Parameter & No additive & $\mathbf{K}_{2} \mathbf{C r}_{2} \mathbf{O}_{7}$ & Monoethanolamine \\
\hline $\mathrm{pH}$ & $\frac{5.6}{7.9}$ & $\frac{4.5}{7.7}$ & $\frac{11.2}{9.7}$ \\
\hline $\begin{array}{c}\text { Corrosion potential } E_{\text {corr }}, \mathrm{mV} \\
(\nu \mathrm{s} . \mathrm{SHE})\end{array}$ & $\frac{-546}{-331}$ & $\frac{-351}{-443}$ & $\frac{-458}{-376}$ \\
\hline Corrosion current $i_{\text {corr }}, \mu \mathrm{A} / \mathrm{cm}^{2}$ & $\frac{28}{72}$ & $\frac{30}{36}$ & $\frac{8}{76}$ \\
\hline Corrosion rate $K, \mathrm{~g} /\left(\mathrm{m}^{2} \cdot \mathrm{h}\right)$ & $\frac{0.28}{0.72}$ & $\frac{0.30}{0.36}$ & $\frac{0.08}{0.76}$ \\
\hline Degree of protection $Z, \%$ & - & $\frac{0}{50}$ & $\frac{71}{-5.5}$ \\
\hline Inhibition factor $Y$ & - & $\frac{1.0}{2.0}$ & $\frac{3.3}{0.95}$ \\
\hline
\end{tabular}


Table 2. Parameters of the Tafel equation $E=a_{i}+b_{i} \cdot \lg i(\mathrm{mV})$ found for anodic $\left(a_{a}\right.$ and $\left.b_{a}\right)$ and cathodic $\left(a_{c}\right.$ and $b_{c}$ ) partial processes on steel St 3 in MSCN (numerator) and ASCN (denominator).

\begin{tabular}{cccc}
\hline Parameter & No additive & $\mathbf{K}_{2} \mathbf{C r}_{\mathbf{2}} \mathbf{O}_{7}$ & Monoethanolamine \\
\hline$a_{a}$ & $\frac{-704}{-243}$ & $\frac{-515}{-296}$ & $\frac{-752}{-276}$ \\
\hline$b_{a}$ & $\frac{43}{89}$ & $\frac{38}{121}$ & $\frac{60}{89}$ \\
\hline$a_{c}$ & $\frac{-883}{-445}$ & $\frac{-685}{-509}$ & $\frac{-569}{-462}$ \\
\hline$b_{c}$ & $\frac{-121}{-76}$ & $\frac{-120}{-14}$ & $\frac{-51}{-76}$ \\
\hline
\end{tabular}
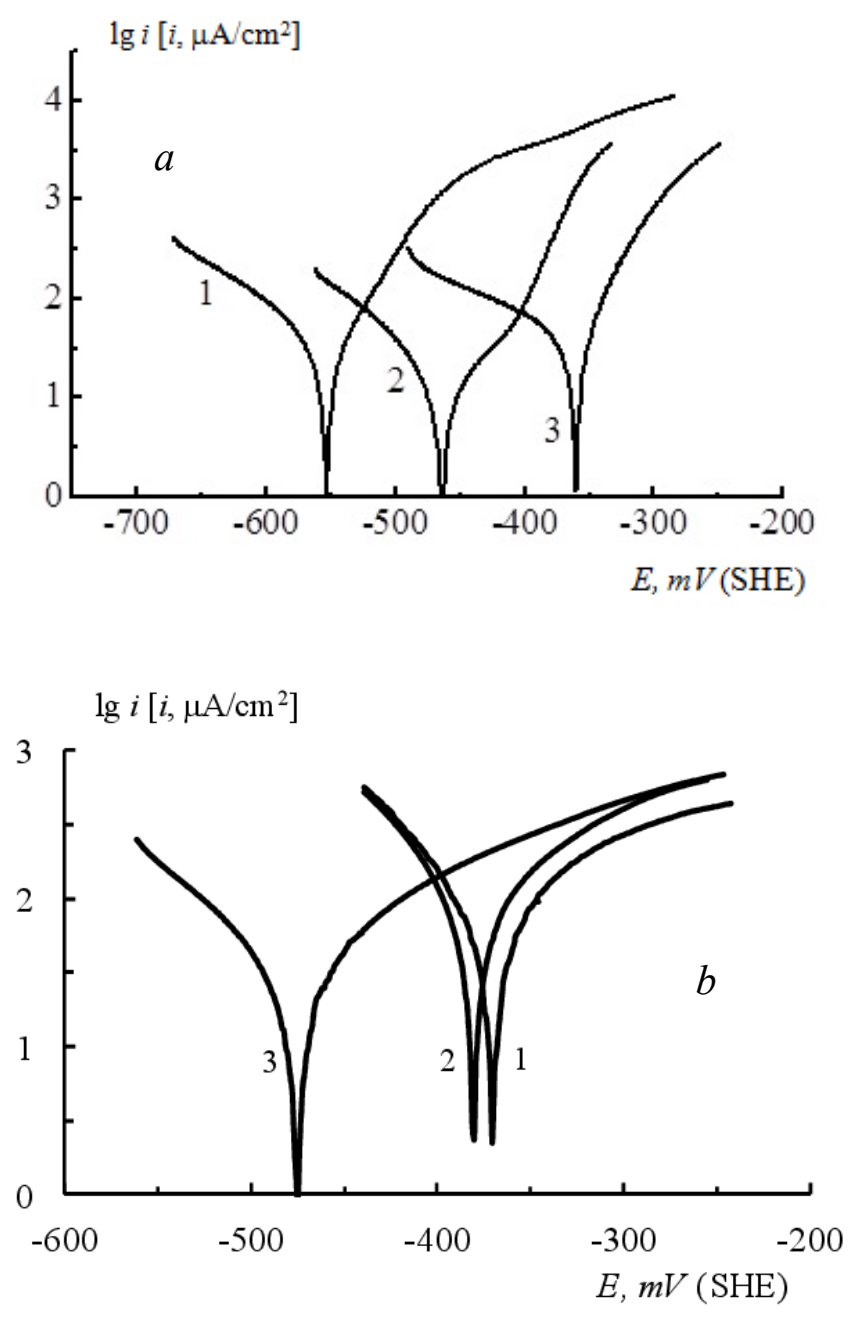

Figure 1. Polarization curves of steel St3 in the model $(a)$ and ammoniated $(b)$ aqueous solutions of calcium nitrate without an inhibitor (1) and in the presence of monoethanolamine (2) and $\mathrm{K}_{2} \mathrm{Cr}_{2} \mathrm{O}_{7}(3)$. 
Analysis of polarization curves obtained in the model solution (Figure $1 a$ ) shows that the open-circuit corrosion potential changes in a positive direction in the presence of both additives, whereas the current of the anodic process at $E=$ const decreases. The effects of the corrosion potential rise and metal dissolution rate decrease are more pronounced with potassium dichromate than with monoethanolamine. The effects of these additives on the cathodic process are converse: the reduction rate does not decrease, but rather increases in the presence of the additives used in this work. Ammonization of the nitrate solution significantly changes the electrochemical behavior of the system (Figure $1 b$ ). In particular, the open-circuit potential in ammoniated solution is significantly more positive than in the model solution, and the additives lead to its decrease.

The Tafel equation parameters (Table 2) found on the linear portions of $E$, lgi curves obtained on steel St3 in the model nitrate electrolyte with various additives indicate that corrosion apparently occurs with hydrogen depolarization. Indeed, the slope of the linear portion of the semilogarithmic cathodic polarization curve is $-120 \mathrm{mV}$ (except in the solution with addition of monoethanolamine), indicating that hydrogen discharge with oneelectron transfer is the limiting step [6,7]. Addition of monoethanolamine as well as ammonization of the calcium nitrate solution reduces its acidity (Table 1), that probably contributes to the realization of a multi-step mechanism of the cathodic process complicated with oxygen depolarization.

A similar effect was observed in the anodic behavior of the steel electrode. In the model solution without an inhibitor and in the presence of potassium dichromate, the slope of the linear plot of anodic current logarithm on potential is $40 \mathrm{mV}$ on average (Table 2). This indicates that the electrochemical reaction of metal dissolution occurs with formation of doubly charged ions by a two-step mechanism with slow detachment of the second electron [6,7]. At the same time, addition of monoethanolamine and transition to ammoniated solution significantly impede the anodic process: the slope of the corresponding section of the $E$, lgi-plot increases to 60-121 mV (Table 2).

The rate of the corrosion process found from $i_{\text {corr }}$ using the Faraday's law in the model solution of calcium nitrate is lower than in the ammoniated solution (Table 1). However, in both cases St3 steel is a material with reduced corrosion resistance.

The protective effect of the additives was evaluated by the degree of protection

$$
Z=\frac{K_{1}-K_{2}}{K_{1}} \cdot 100 \% \equiv \frac{i_{\text {corr }, 1}-i_{\text {corr }, 2}}{i_{\text {corr }, 1}} \cdot 100 \%
$$

and inhibition factor

$$
Y=\frac{K_{1}}{K_{2}} \equiv \frac{i_{\text {corr }, 1}}{i_{\text {corr }, 2}}
$$

Here $K_{1}\left(i_{\text {corr, }, 1}\right)$ and $K_{2}\left(i_{\text {corr, } 2}\right)$ are the rates (current densities) of steel dissolution in the solution without and in the presence of an additive, correspondingly. These parameters 
(Table 1) are found from the intersection of linear semilogarithmic plots of the polarization curves corresponding to the partial processes on the steel in the environments studied.

Addition of potassium dichromate to the model solution significantly reduces the rate of anodic dissolution of steel but increases the rate of the cathodic reaction (Figure 1a). As a result, despite the shift of the corrosion potential in the positive direction, the corrosion rate is almost unchanged compared to the initial nitrate solution. The anodic reaction rate is reduced to a greater extent than the cathodic reaction rate in the case of monoethanolamine, and therefore the rate of the corrosion process decreases in general. Monoethanolamine also reduces the rate of anodic dissolution of steel in the ammoniated solution of calcium nitrate. However, the cathodic reaction rate increases, despite the shift of the corrosion potential in the positive direction. As a result, the corrosion rate is practically unchanged compared to the solution without additives. In the case of potassium dichromate as an additive to ASCN, the rate of the corrosion process is markedly reduced.

\section{Conclusion}

Low carbon steel St3 in the initial solution of calcium nitrate and with addition of potassium dichromate is a material with reduced corrosion durability. The organic additive (monoethanolamine) increases the resistance of St3 steel to corrosion. In ammoniated solution of $\mathrm{Ca}\left(\mathrm{NO}_{3}\right)_{2}$ without an additive, as well as with addition of monoethanolamine, steel St3 can be considered as a resistant material, while addition of potassium dichromate to ASCN allows us to consider this steel as an extremely corrosion resistant material.

\section{References}

1. H. Justnes and E. C. Nygaard, Cement and Concrete Research, 1995, 25, no. 8, 1766.

2. H. Justnes and E. C. Nygaard, Proceedings of the International Conference on HighPerformance Concrete, and Performance and Quality of Concrete Structures, 1996, June 05-07, Florianopolis, Brazil, 514.

3. F. Karagöla, R. Demirboğaa, M. A. Kaygusuzc, M. M. Yadollahia and R. Polata, Cold Regions Science and Technology, 2013, 89, no. 5, 30.

4. S. A. Ryabokon', Tekhnologicheskie zhidkosti dlya zakanchivaniya i remonta skvazhin (Process liquids for well completion and workover), Burenie Publishing Company, Krasnodar, 2006 (in Russian).

5. N. I. Yurkiv, A. I. Sh. Saleh and I. G. Tsigelnitsky, Teplonositel'-antifriz: patent na izobretenie (Coolant-antifreeze: invention patent), Patent RU 2116326, appl. 25.02.1997, publ. 07.27.1998 (in Russian).

6. H. H. Uhlig and R. W. Revie, Corrosion and Corrosion Control, Wiley-Interscience, 1985.

7. A. J. Bard, M. Stratmann and G. S. Frankel, Encyclopedia of electrochemistry: corrosion and oxide films, WileyVCH, 2007. 